Mirela L. S. Gomes

(ㄱ) https://orcid.org/0000-0003-1626-4425

Humberto Corrêa ${ }^{2}$

(- https://orcid.org/0000-0003-4327-6413

Dante Duarte

(ํ) https://orcid.org/0000-0001-7516-5473

Sarah Rück| ${ }^{4}$

Ohttps://orcid.org/0000-0002-5413-9847

Mayara Yara Martins Brancaglion²

Ohttps://orcid.org/0000-0001-9662-7753

Maria Frasson ${ }^{1}$

Ohttps://orcid.org/0000-0002-1250-3575

\section{Depression and quality of life in individuals with Stargardt's disease}

\author{
Depressão e qualidade de vida em indivíduos com doença de Stargardt
}

DOI: $10.1590 / 0047-2085000000257$

\begin{abstract}
Objectives: To assess depression and quality of life in individuals with Stargardt's disease (SD), macular dystrophy whose central vision loss begins in the first decades of life. Methods: This observational, cross-sectional study included 41 SD patients and 46 healthy controls, aged 18 to 63 years old, in Minas Gerais, Brazil. Major depression episode was assessed by the Mini International Neuropsychiatric Interview, depressive symptomatology by the Beck Depression Inventory (BDI) and Hamilton Depression Scale (HAM-D) and quality of life by the National Eye Institute Visual Function Questionnaire. The comparison between sociodemographic variables, quality of life and depression was performed using Fisher's exact test and Mann-Whitney-Wilcoxon test. Results: The prevalence of depression was $12.2 \%$ in the sample with SD while in the control group was $8.7 \%(p=0.614)$. No significant differences were observed between patients and the control group regarding the prevalence of depression and sociodemographic variables. Patients with SD had overall lower quality of life scores (59.7 vs. 88.7, p $<0.001$ ), and presented inverse correlation between depressive symptoms, as assessed by BDI (Rho $=-0.49, p<0.001)$ and by HAM-D (Rho $=-0.45, p=0.003$ ) with quality of life scores. Conclusion: Depressive symptoms were the major factors affecting quality of life, regardless of sociodemographic data. Individuals with SD may develop copying strategies, seek mental care to prevent the increase of depression and decrease of quality of life.
\end{abstract}

\section{KEYWORDS}

Stargardt's disease, visual impairment, depression, quality of life.

\section{RESUMO}

Objetivos: Avaliar a depressão e a qualidade de vida em indivíduos com doença de Stargardt (DS), distrofia macular cuja perda de visão central se inicia nas primeiras décadas de vida. Métodos: Este estudo observacional e transversal incluiu 41 pacientes com DS e 46 controles saudáveis, com idades entre 18 e 63 anos, em Minas Gerais, Brasil. Episódio de depressão maior foi avaliado pelo Mini Internacional Neuropsychiatric Interview (MINI)-PLUS, a sintomatologia depressiva, pelo Inventário de Depressão de Beck (BDI) e pela Escala de Depressão de Hamilton (HAM-D) e a qualidade de vida, pelo Questionário de Função Visual do Instituto de Olhos Nacional versão de 25 itens (NEI VFQ-25). A comparação entre as variáveis sociodemográficas, a qualidade de vida e a depressão foi realizada por meio do teste exato de Fisher e o teste de Mann-Whitney-Wilcoxon. Resultados: A prevalência de depressão foi de 12,2\% na amostra com indivíduos com DS, enquanto no grupo controle foi de $8,7 \%$ ( $p=0,614)$. Não foram observadas diferenças significativas entre os pacientes e o grupo controle quanto à prevalência de depressão e às variáveis sociodemográficas. Os pacientes com DS apresentaram menor pontuação geral de qualidade de vida $(59,7$ vs. 88,7, p < 0,001), cujas variáveis com correlação inversa e estatisticamente significante $(p<0,05)$ foram as de sintomatologia depressiva, avaliadas pelo BDI $(R h o=-0,49, p<0,001)$ e pelo HAM-D (Rho = -0,45, $\mathrm{p}=0,003)$. Conclusão: Os sintomas depressivos foram os principais fatores que afetaram a qualidade de vida, independentemente dos dados sociodemográficos. Indivíduos com DS podem desenvolver estratégias de enfrentamento e procurar assistência mental para evitar o aumento da depressão e a diminuição da qualidade de vida.

\section{PALAVRAS-CHAVE}

Doença de Stargardt, deficiência visual, depressão, qualidade de vida.
Received in: Jan/27/2020. Approved in: Feb/11/2020

1 Department of Ophthalmology, Federal University of Minas Gerais, Belo Horizonte, MG, Brazil.

2 Department of Psychiatry, Federal University of Minas Gerais, Belo Horizonte, MG, Brazil.

3 Spaulding Neuromodulation Center, Harvard Medical School, Boston, MA, USA.

4 Department of Forensic Medicine and Psychiatry, Federal University of Paraná, Curitiba, PR, Brazil.

Address for correspondence: Mirela L. S. Gomes. Federal University of Minas Gerais, Department of Ophthalmology, São Geraldo Hospital - Vítreo e Retina Department. Alfredo Balena Avenue, 190, Santa Efigênia - 30130-100 - Belo Horizonte, MG, Brazil. E-mail: mirelasantana02020@gmail.com 


\section{INTRODUCTION}

Stargardt disease (SD) is the most common form of juvenile onset macular dystrophy, with a prevalence of 1:10,000'. Symptoms are characterized by irreversible bilateral central vision loss in the first or second decade of life 2,3 . The visual acuity in many cases may be lower than 0.1 (severe low vision) and there is no effective medical treatment for this complex pathology plenty of comorbidities at the moment ${ }^{1,2}$.

Visual impairment affects quality of life and relates to neuropsychiatric comorbidities such as major depressive disorder (MDD) $)^{4}$. In fact, in a representative sample of adults, the estimated prevalence of depression was $11,3 \%$ among those with visual loss and $4.8 \%$ among those without it ${ }^{5}$. This rate of depression is comparable to that of other chronic diseases, such as diabetes mellitus (11\%-31\%) and arthritis $(10-24 \%)^{6}$. and as depression is the leading cause of disability worldwide the identification of cases is of utmost importance ${ }^{3}$.

The present study aims to compare the prevalence of MDD in SD patients with health control (sighted adults) and to investigate the association between quality of life and depressive symptoms. We hypothesize that subjects with SD will present more depressive symptoms affecting negatively quality of life indicators.

This study was approved by the UFMG Research Ethics Committee according to the consubstantiated 3,369,000.

\section{METHODS}

Sixty-two medical records from January 2016 to September 2017 of patients with SD treated at the Department of Retina - Federal University of Minas Gerais were evaluated. SD diagnosis was confirmed based on family history, ophthalmologic examination, and electroretinography recordings, following the International Society for Clinical Electrophysiology of Vision criteria ${ }^{7}$.

The inclusion criteria were: documented best corrected visual acuity (BCVA) ranging from 0.1 to 0.05 (severe low vision)', aged from 18 to 63 years, absence of other ophthalmological diseases and stable medical condition.

Forty-one patients (medical records) who fulfill the inclusion criteria were selected and forty-six age- and sex-matched healthy volunteers with acuity visual of 1,0 (normal vision) were recruited from the waiting room. All 87 participants underwent an ophthalmologic examination, which included the following tests: BCVA with manifested refraction by Snellen visual chart, slit-lamp biomicroscopy of anterior segment and fundus examination.

The study adhered to the tenets of the Declaration of Helsinki and was approved by the Federal University of Minas Gerais ethics committees (CAAE no. 04151118.2.0000.5149). All participants signed an informed consent form and were interviewed by a trained psychiatrist using the Mini International
Neuropsychiatric Interview (MINI-Plus) to evaluate current psychiatric diagnosis. Additionally, they were assessed by Beck Depression Inventory (BDI), Hamilton Depression Rating Scale (HAM-D) and 25-item version of the National Eye Institute Visual Function Questionnaire (NEI VFQ-25) in order to assess current clinical symptoms and quality of life.

The MINI-Plus is a structured diagnostic interview of psychiatric disorders, compatible with the DSM-V criteria ${ }^{8}$. In the present study, only the MDD module was administered and to assess current depressive symptoms.

The $\mathrm{BDI}$ is a self-report instrument, validated for the Brazilian population to quantify symptoms of depression?. It has 21 items in an ordinal scale of 0-3 and the cutoff point of 16 was used to differentiate between presence and absence of depression ${ }^{10}$. Accordingly, the HAM-D is an examiner-applicable questionnaire validated for the Brazilian population with 17 item and scores ranging from 0 to 49 11,12, the highest overall score implies severe depression ${ }^{13}$.

Quality of life may be estimated by questionnaires assessing performance of self-perceived daily activities and functioning on physical, mental and social health. The NEI VFQ-25 questionnaire measures psychosocial aspects of the quality of life that belong to visual functioning in everyday life in people with chronic eye diseases. It is composed of 12 subscales: general health and general vision, near vision, distance vision, driving, peripheral vision, color vision, ocular pain, specific visual limitations (role difficulties), dependency, social functioning, and mental health. In each of the subscales, the scores are converted to a 0 to 100 scale, so higher scores mean better visual functioning ${ }^{14}$. In the present study we have omitted the driving subscale because our patients were unable to perform this activity.

The sample size necessary to detect a 15\% difference in the prevalence of depression between individuals with SD and the control group was determined assuming an alpha of $5 \%$ and a power of $80 \%$ in a two-tail test. To detect the difference of $15 \%$ between study groups and to provide at least $80 \%$ power the estimated sample size is 40 individuals in each group with a total of 80 individuals $^{15}$.

The statistical program software $R$ version 3.4.1 was used for the analysis. Binary variables were compared between different groups using Fisher's exact test with mid-p method (odds ratio function of the epitools library). Continuous variables when normally distributed were compared using T-test and when not-normally distributed were compared using the Mann-Whitney-Wilcoxon test.

\section{RESULTS}

Eighty-seven participants were recruited for the study, 46 health controls and 41 patients with SD. The mean age of the participants with SD was 37.5 years (SD \pm 13.7$)$ and $68,3 \%$ 
were female $(n=28 / 41)$. The current estimated prevalence of depression in the sample with SD was $12.2 \%$ and $8.7 \%$ among volunteers $(p=0.614)$.

No significant differences were observed between the two groups regarding socio-demographic and clinicals variables, including gender, age, educational level, prevalence of depression (past and current) and monthly family income (Table 1).

There was statistically significant difference between individuals with SD and controls concerning quality of life assessed by the NEI VFQ-25 ( $p<0.001)$. In addition, the mean of years living with low vision was 19.6 years (SD \pm 9.8 ) and the mean age at diagnosis of SD was 13 years (SD \pm 8.0 ), most of them (70.7\%) used low vision aids (magnifying glass and telescope). The mean of years of academic achievement were $14.5(S D \pm 6.0)$.

Table 2 presents correlation coefficients between the NEI-VFQ-25 scores and clinical variables in the group with SD. Significant inverse correlation was found with depressive symptomatology: BDI's (Rho $=-0.49, \mathrm{p}<0.001)$ and HAM-D (Rho $=-0.45, p=0.003)$ and direct correlation with family wage $(R h o=0.37, p=0.019)$.

\section{DISCUSSION}

To the best of our knowledge, this is the first study estimating the current prevalence of depression in Brazilian patients with SD, as well as to analyze the correlation between quality of life and depressive symptomatology in this population. The prevalence of MDD in our sample with SD is $12.2 \%$, similar to $11.3 \%$ for people with visual impairment and $12.6 \%$ for young people in southern Brazi|3,10.
Our results demonstrated lower quality of life scores (59.7 \pm 14.4$)$ in patients with SD compared to controls replicating findings from previous studies, $4,14,16,17$. Indeed, the central visual - lost in Stargardt disease - is used in most tasks performed in daily life such as reading, visual perception of distance and face recognition. Therefore, visual loss contributes to functional limitations and hamper the quality of life ${ }^{14,16}$. Interestingly, some patients are able to engage into compensatory strategies using retinal periphery (optimizing brain plasticity) during reading $1,2,16,17$. Such findings could justify educational levels attained by the two groups in our study. Supporting our hypotheses, depressive symptoms measured by BDI and HAM-D were correlated with NEI VFQ-25. These findings are consistent with previous study, in which patients with depressive symptoms had poorer quality of life compared with patients without depression, in which could not be explained by visual loss, age or disease duration ${ }^{4,10}$.

Table 2. Correlations between clinical outcomes and NEI-VFQ-25 composite scores

\begin{tabular}{lcc}
\hline Variables & Spearman's Rho & p \\
\hline Age & -0.28 & 0.077 \\
Educational level (years) & 0.21 & 0.18 \\
Family wage & 0.37 & 0.019 \\
Years of low vision & -0.24 & 0.138 \\
Years at diagnosis & -0.04 & 0.827 \\
Visual Acuity (both eyes) & 0.14 & 0.39 \\
HAM-D & -0.45 & 0.003 \\
BDI & -0.49 & 0.001 \\
\hline
\end{tabular}

$\mathrm{N}=$ number of patients; $\mathrm{SD}=$ standard deviation.

Table 1. Demographic and visual data, major depression disorder and depressive symptomatology between Stargardt disease patient and health controls

\begin{tabular}{|c|c|c|c|c|c|}
\hline \multirow{2}{*}{ Variables } & \multicolumn{2}{|c|}{ Controls $(\mathrm{N}=46)$} & \multicolumn{2}{|c|}{ SD patients $(\mathrm{N}=41)$} & \multirow{2}{*}{$\mathbf{p}$} \\
\hline & $\mathbf{N}$ & $\%$ & $\mathbf{N}$ & $\%$ & \\
\hline Male & 16 & 34.8 & 13 & 31.7 & 0.768 \\
\hline Employed/retired & 33 & 71.7 & 30 & 73.2 & 0.886 \\
\hline Low vision aids & - & - & 29 & 70.7 & - \\
\hline Past Depressive Episode (MINI) & 19 & $41.3 \%$ & 18 & $43,9 \%$ & $0.811^{*}$ \\
\hline Current Depressive Episode (MINI) & 4 & $8.7 \%$ & 5 & $12.2 \%$ & $0.614^{*}$ \\
\hline Variables & \multicolumn{2}{|c|}{ Mean (SD) } & \multicolumn{2}{|c|}{ Mean (SD) } & $\mathbf{p}$ \\
\hline Age & 38.7 & $(13.7)$ & 37.5 & $(13.70)$ & 0.714 \\
\hline Educational level (years) & 15.2 & (3.4) & 14.5 & $(6.0)$ & 0.450 \\
\hline Family wage & 1.9 & $(0.7)$ & 1.9 & $(0.6)$ & 0.831 \\
\hline Years of low vision & - & - & 19.6 & (9.8) & \\
\hline Years at diagnosis of SD & - & - & 13.0 & (8.0) & \\
\hline NEI-VFQ-25 (Total) & 88.7 & (9.3) & 59.7 & $(14.4)$ & $<0.001$ \\
\hline HAM-D & 3.4 & $(5.0)$ & 4.8 & (8.4) & $0.526+$ \\
\hline $\mathrm{BDI}$ & 4.9 & (6.7) & 5.0 & $(10.3)$ & $0.176+$ \\
\hline
\end{tabular}

Footnote: $\mathrm{N}$ = number of patients; $\mathrm{SD}=$ standard deviation; * Fisher exact test with mid-p method; + Mann-Whitney-Wilcoxon test. 
The relationship between quality of life and depression is complex, because depression may decrease quality of life and vice versa. ${ }^{5,16}$ Although it is not possible from this cross-sectional analysis to determine whether depression is a cause or an effect of quality of life, it may be inferred that subjects with SD and depressive symptoms represent a high risk group for impaired quality of life and ultimately more vulnerable to chronic conditions. Additionally, patients who are depressed may not seek out eye care when experiencing visual problems undermining treatment adherence ${ }^{5}$. Thus, ophthalmologists and vision professionals should be educated to identify early depressive symptoms ${ }^{3}$.

Our study has several strengths such as well powered and addressing a rare and important condition but also presents some limitations. Given the cross-sectional design, causality and temporal inferences cannot be drawn. Finally, people with severe depression might have avoided to enroll in the study influencing a selection bias and potentially underestimating the prevalence of depression in SD patients.

\section{CONCLUSIONS}

Although the results of the present study did not identify increment in prevalence of MDD in SD sample compared with volunteers, depressive symptoms were the strongest contributing factor influencing the quality of life. Therefore, patients with SD should be extensively screened for depression.

\section{INDIVIDUAL CONTRIBUTIONS}

Mirela L. S. Gomes - Had contributed to conception, design, analysis and interpretation of data, revising and had given the final approval of the version to be published.

Humberto Corrêa - Had contributed to conception, revising and had given the final approval of the version to be published.

Dante Duarte - Had contributed to analysis, revising and had given the final approval of the version to be published.

Sarah Rückl - Had contributed to design, revising and had given the final approval of the version to be published.

Mayara Y. M. Brancaglion - Had contributed to interpretation of data, revising and had given the final approval of the version to be published.

Maria Frasson - Had contributed to conception, design and interpretation of data, revising and had given the final approval of the version to be published.

\section{CONFLICTS OF INTEREST}

No authors have any funding, financial, or conflicting interest to disclose.

\section{ACKNOWLEDGMENTS}

We thank Alessandra Almeida Carvalho for assisting in patient selection.

\section{REFERENCES}

1. Rotenstreich Y, Fishman GA, Anderson RJ. Visual acuity loss and clinical observations in a large series of patients with Stargardt disease. Ophthalmol. 2003;110(6):1151-8.

2. Testa F, Melillo P, Di lorio V, Orrico A, Attanasio M, Rossi S, et al. Macular function and morphological features in juvenile Stargardt disease: Longitudinal study. Ophthalmol. 2014;121(12):2399-405

3. Moschos MM, Nitoda E, Lavaris A. Estimation of depression prevalence in patients with Stargardt disease using PHQ-9 and Zung scores. Eur J Ophthalmol. 2016;26(3):268-72.

4. Hahm BJ, Shin YW, Shim EJ, Jeon HJ, Seo JM, Chung H, et al. Depression and the vision-related quality of life in patients with retinitis pigmentosa. $\mathrm{Br} J$ Ophthalmol. 2008;92(5):650-4.

5. Zhang X, Bullard KM, Cotch MF, Wilson MR, Rovner BW, McGwin G, et al. Association between depression and functional vision loss in persons 20 years of age or older in the United States, NHANES 2005-2008. JAMA Ophthalmol. 2013;131(5):573-81.

6. Read JR, Sharpe L, Dear BF. Multimorbidity and depression: A systematic review and metaanalysis. J Affect Disord. 2017;221:36-46.

7. Lois N, Holder GE, Bunce C, Fitzke FW, Bird AC. Phenotypic subtypes of Stargardt macular dystrophy-fundus flavimaculatus. Arch 0phthalmol. 2001;119(3):359-69.

8. Amorim P. Mini International Neuropsychiatric Interview (MINI): validação de entrevista breve para diagnóstico de transtornos mentais. Rev Bras Psiquiatr. 2000;22(3):106-15.

9. Gorenstein C, Andrade L. Inventário de Depressão de Beck: propriedades psicométricas da versão em português. Rev Psiquiatr Clin. 1998;25(5):245-50.

10. Lopez MRA, Ribeiro JP, Ores LC, Jansen K, Souza LDM, Pinheiro RT, et al. Depressão e qualidade de vida em jovens de 18 a 24 anos no sul do Brasil. Rev Psiquiatr Rio Gd Sul. 2011;33(2):103-8

11. Carvalho FR, Lima MG, Azevedo RCS, Caetano D. Tradução do inglês para o português do Questionário de Autoavaliação da Escala de Hamilton para a depressão. J Bras Psiquiatr. $1993 ; 42(5): 255-60$

12. Freire MÁ, Figueiredo VLM, Gomide A. Hamilton Scale: study of the psychometric characteristics in a sample from Southern Brazil. J Bras Psiquiatr. 2014;63(4):281-9.

13. Hamilton M. A rating scale for depression. J Neurol Neurosurg Psychiat. 1960;23(56):56-62.

14. Mangione CM, Lee PP, Gutierrez PR. Development of the 25-item National Eye Institute Visual Function Questionnarie. Arch Ophthalmol. 2001;119(7):1050-8.

15. Chow SC, Shao J, Wang H. Sample size calculations in clinical research. 2nd ed. Boca Raton: Chapman \& Hall/CRC Biostatistical series; 2008.

16. Szlyk JP, Fishman GA, Grover S, Revelins BI, Derlacki DJ. Difficulty in performing everyday activities in patients with juvenile macular dystrophies: comparison with patients with retinitis pigmentosa. Br J Ophthalmol. 1998;82(12):1372-6.

17. Murro V, Sodi A, Giacomelli G, Mucciolo DP, Pennino, M, Virgili G, et al. Reading ability and quality of life in Stargardt disease. Eur J Ophthalmol. 2017;27(6):740-5. 